\title{
Endogenous Market Structures and Innovation
}

\author{
Federico Etro \\ University of Venice, Ca' Foscari
}

First Draft: December 2010

\begin{abstract}
One of the pioneering works on endogenous market structures, by Tandon (1984), has extended the standard Cournot model with linear demand to endogenous entry and sunk R\&D costs to show that the endogenous number of firms is independent from the size of the market. I generalize the model in many directions and show that, as long as the exogenous fixed costs are positive, the endogenous market structure is naturally characterized by an inverted-U relation between market size and number of firms, in line with the celebrated hypothesis of Sutton (1991).
\end{abstract}

\section{Keywords}

Oligopoly, Endogenous entry, Sunk costs, R\&D investment

\section{JEL Codes}

L1

Address for correspondence:

Federico Etro

Department of Economics

Ca’ Foscari University of Venice Cannaregio 873, Fondamenta S.Giobbe 30121 Venezia - Italy

Phone: (++39) 3294454955

Fax: (++39) 0412349176

e-mail: federico.etro@unive.it

This Working Paper is published under the auspices of the Department of Economics of the Ca' Foscari University of Venice. Opinions expressed herein are those of the authors and not those of the Department. The Working Paper series is designed to divulge preliminary or incomplete work, circulated to favour discussion and comments. Citation of this paper should consider its provisional character.

The Working Paper Series
is availble only on line
(www.dse.unive.it/pubblicazioni)
For editorial correspondence, please contact:
wp.dse@unive.it


The endogenous market structure approach analyzes strategic interactions between an endogenous number of competitors. One of the leading themes of this approach, emphasized in the empirical work of Sutton (1991), is about the role of R\&D investment in determining the size of the fixed costs of production and, through them, the structure of the markets. One of the pioneering theoretical works in the field, by Tandon (1984), has extended the standard Cournot model with linear demand to endogenous entry and sunk costs to show that the endogenous number of firms is independent from the size of the market and above optimal. Tandon (1984) focused on a very specific example, but he supported an analogous result on size-neutrality obtained by Dasgupta and Stiglitz (1980) in a Cournot model with isoelastic demand. This independence of the number of firms from the size of the market anticipated the celebrated result by Sutton (1991) of a lower positive bound to market concentration in the presence of endogenous sunk investments - see Vives (2008) for a recent generalization. These investments, for instance in R\&D or advertising, are essential for the result because the number of firms remains constant only when the endogenous sunk costs increase proportionally with the size of the market. ${ }^{1}$ Sutton (1991) has also emphasized the possibility of a non-monotone relation between size and entry, but only due to a shift of regime from a traditional one with zero endogenous investment for all firms (where a larger size increases the number of firms) to an "escalation"

\footnotetext{
${ }^{1}$ The number of firms is always increasing in the market size when the entry cost is fully exogenous.
} 
phase in which market expansion leads to higher investments and higher concentration (a larger size reduces the number of firms). A wide empirical literature, has also verified the hypothesis of an inverted- $U$ relation between market size and number of firms for markets with endogenous sunk costs. The initial reference is Sutton (1991). Recently, Ellickson (2007) has looked at the supermarket industry in the U.S. and shown that "the minimum level of concentration is highest in the smallest markets, decreases for a range, and then hits a lower limit beyond which it does not fall and might even increase" (p. 52).

Here, I generalize the example by Tandon (1984) in many directions and show that, as long as the exogenous fixed costs are positive, the endogenous market structure is naturally characterized by an inverted-U relation between market size and number of firms, in line with the hypothesis of Sutton (1991). Firms invest always in sunk costs, here aimed at cost reductions, and their investment increases with the size of the market. However, the number of firms is increasing in size for small markets and reaches a maximum for some intermediate size, beyond which further expansion leads to a reduction of the number of competitors.

The next section presents the model, the following two extend it to general cost reduction technologies and sequential decisions on $\mathrm{R} \& \mathrm{D}$ investment and production, and the last section concludes. 


\section{Endogenous Market Structures and Sunk Costs}

Consider $S$ consumers with individual demand $a-p$ for a given price $p$ and a constant $a>0$, so that the inverse demand for a total quantity $X$ is given by:

$$
p=a-\frac{X}{S}
$$

Competition takes place between $n$ firms which simultaneously choose production and investment. The marginal cost of production of firm $i=1,2, \ldots, n$ is $c-z_{i}^{\alpha}$ where $c>0$ is the baseline marginal cost and $\alpha<1$. The cost reduction activity requires an investment $\theta z_{i}$, with $\theta>0$. The exogenous fixed cost of production is $F \geq 0$.

Tandon (1984) assumes that $a=c$ and that $F=0$ and, to avoid explosive investment, he focuses on technologies with low productivity, namely with $\alpha<1 / 2$ : as we will see, these assumptions together lead to the independence of the number of firms from the market size. We generalize his model with $a>c$ and we introduce a positive exogenous entry cost $F>0$. However, to obtain closed form solutions, we initially solve the case with $\alpha=1 / 2$ (below we relax also this assumption). The profit function of a firm $i=1,2, \ldots, n$ is:

$$
\pi_{i}=\left(a-\frac{X}{S}\right) x_{i}-\left(c-\sqrt{z_{i}}\right) x_{i}-\theta z_{i}-F
$$

where $x_{i}$ is the production of firm $i$. Imagine that all the firms choose simultaneously the investment $z_{i}$ and the production level $x_{i}$. In a symmetric equilibrium, this implies 
a common $R \& D$ investment:

$$
z=\frac{(a-c)^{2}}{[2 \theta(n+1) / S-1]^{2}}
$$

and a production $x=2 \theta \sqrt{z}$. Entry occurs until net profits are zero, which generates the R\&D investment:

$$
z^{*}=\frac{F S}{(4 \theta-S) \theta}
$$

and the following number of firms:

$$
n^{*}=\frac{a-c}{2 \sqrt{F}} \sqrt{4 S-\frac{S^{2}}{\theta}}+\frac{S}{2 \theta}-1
$$

Notice that we assume a limit on the $R \& D$ activity $c \geq \sqrt{z}$ which makes sure that the marginal cost is at most reduced to zero. This imposes an upper bound on size $\bar{S}=4 \theta /\left(1+F / \theta c^{2}\right)$. Beyond that bound, all firms invest $z=c^{2}$ and the Cournot equilibrium with zero marginal costs and endogenous entry induces the classic positive relation between size of the market and number of firms, namely with $n=a \sqrt{S /\left(F+\theta c^{2}\right)}-1$. For our purposes, it is natural to assume that the marginal cost of $\mathrm{R} \& \mathrm{D} \theta$ is high enough to exclude this region in which additional innovations are impossible.

Let us analyze the equilibrium number of firms (3). First of all notice that when the positive exogenous sunk cost $F$ goes to zero the endogenous investment $z^{*}$ goes to zero as well, and the number of firms goes to infinity: in spite of the endogenous 
sunk costs, the lower bound on concentration is always zero. The reason is that entry reduces individual sales, profits and incentives to invest, and all of them must vanish (in the long run) when there are not exogenous obstacles to entry. This should not be surprising because the model does not satisfy the conditions found by Sutton (1991) and Vives (2008) for an upper bound on the number of firms. If the elasticity of inverse demand $p(X)$ is $\epsilon(X)=-X p^{\prime}(X) / p(X)$ and that of the marginal cost $c(z)$ is $\gamma(z)=-z c^{\prime}(z) / c(z)$, Vives (2008) shows that a bound exists when these elasticities are limited respectively above by $\hat{\epsilon}$ and below by $\hat{\gamma}$ - then the maximum number of firms is $\hat{\epsilon}(1+1 / \hat{\gamma})$. Neither one or the other elasticity is bounded in our model.

When the fixed cost is positive, the function of the number of firms is concave and increasing (decreasing) in $S$ for $S$ below (above) the cut-off:

$$
\hat{S}=2 \theta\left[1+\sqrt{\frac{F}{F+\theta(a-c)^{2}}}\right]
$$

Therefore, we obtain an upper bound on the number of firms, and we also obtain that (3) exhibits an inverted-U relation between $n^{*}$ and $S$. Notice that $\hat{S}$ is always below the upper bound on size $\bar{S}$ for a small enough fixed cost (the former being increasing and the latter decreasing in $F$ ).

To understand the rationale for the non-monotone relation between size and entry notice from (2) that the $R \& D$ investment increases more than proportionally with the size of the market. In small markets with few firms and low investment, the mark ups are high enough that an increase in demand is able to expand production and profits 
as much as needed to attract a larger number of firms. However, in larger markets with many firms, high investments and with low mark ups, an increase in demand cannot expand production enough to increase profits and attract more firms. For a given high number of firms, an expansion of the market is going to increase the entry costs more than the gross profits, which in equilibrium requires a smaller number of active firms. Therefore, the number of firms (3) is maximized for an intermediate size $\hat{S}$, which corresponds to:

$$
\hat{n}^{*}=\sqrt{1+\frac{\theta(a-c)^{2}}{F}}
$$

. Beyond this number, market growth is going to increase concentration.

Finally, notice that other traditional and recent results of the endogenous market structure approach (obtained without endogenous sunk costs) hold here as well. First, it can be verified that the equilibrium number of firms (3) is always above the second best one which maximizes consumer surplus net of production costs taking as given the equilibrium strategies as in Mankiw and Whinston (1986). For instance, when $S=\theta=1$, the optimal number is:

$$
n=\max \left(1, \frac{a-c}{2 \sqrt{F}} \sqrt{\frac{a-3 c}{a-c)}}-\frac{1}{2}\right)<n^{*}
$$

Second, a firm able to pre-commit to its strategies before the competitors would produce more to deter or limit entry inducing a welfare increase (Etro, 2008, 2010; Kovac et al., 2010). 
Third, the equilibrium price is still decreasing in the size of the market $S$ :

$$
p=c+(2 \theta-S) \sqrt{\frac{F}{(4 \theta-S) \theta S}}
$$

which is above (below) the baseline marginal cost $c$ when the market size $S$ is below (above) $2 \theta$, and is always decreasing with $S$ :

$$
\frac{d p}{d S}=-\sqrt{\frac{F}{(4 \theta-S) \theta S}}\left[1+\frac{(2 \theta-S)^{2}}{4 \theta-S}\right]<0
$$

which implies countercyclical prices (Etro and Colciago, 2010). Therefore, concentration should be negatively correlated with prices only in small markets, but not in large ones.

Last, since goods are homogenous and welfare is inversely related to the price, an increase in market size, for instance due to openness to trade, is going to make consumers better off: there are gains from trade due to higher $R \& D$ and lower prices, and any industrial or trade policy aimed at reducing the costs of a domestic firm would increase its production, reduce entry of other firms and enhance welfare (Etro, 2011).

\section{Generalizing the R\&D Technology}

Our main result holds also for general values of $\alpha$ in the cost reduction technology $z_{i}^{\alpha}$. In equilibrium, effort $z(S)$ must satisfy:

$$
z^{2(1-\alpha)}=(\theta \alpha)^{2} S(\theta z+F)
$$


and the number of firms is given by:

$$
n^{*}=\frac{\alpha \theta(a-c) S}{z(S)^{1-\alpha}}+\alpha \theta S z(S)^{2 \alpha-1}-1
$$

In the limit case with $F=0$ we are back to the model of Tandon (1984) where we have:

$$
z(S)=\left(\theta^{2} \alpha^{2} S\right)^{\frac{1}{1-2 \alpha}}
$$

and, assuming $\alpha<1 / 2$, the number of firms is independent from the size of the market if $c=a$, with the result of Tandon (1984):

$$
n^{*}=\frac{1}{\theta \alpha}-1
$$

or it is decreasing in size when $c<a$.

However, for $F>0$ the derivative of $d n^{*} / d S$ has an ambiguous sign, and a non-monotone relation typically emerges, with our previous example occurring when $\alpha=1 / 2$

\section{R\&D Precommitments}

The inverted-U relation shows up also when the strategies are taken sequentially, investment first and production after (as assumed by Sutton, 1991). Returning to the case with $\alpha=1 / 2$, we can easily solve for the Cournot equilibrium in the last stage as a function of the different investments. In the first stage, the equilibrium 
effort can be derived as

$$
z=\frac{(a-c)^{2}}{\left[\theta(n+1)^{2} / n S-1\right]^{2}}
$$

which generates the final production:

$$
x=\frac{\theta(n+1)(a-c) S}{\theta(n+1)-n S}
$$

The profits are given by:

$$
\pi=\frac{\theta(a-c)^{2} S\left[\theta(n+1)^{2}-n^{2} S\right]}{\left[\theta(n+1)^{2}-n S\right]^{2}}-F
$$

which is decreasing in the number of firms $n$, but non-monotone in $S$. As a consequence, also the endogenous number of firms (which sets profits equal to zero) must exibit non-monotonicity. For instance, with $\theta=1$ we obtain the equilibrium number:

$$
n^{*}=\frac{(a-c)^{2} S}{F}-\sqrt{\frac{(a-c)^{4} S^{2}}{F^{2}}-\frac{1}{2}}-\frac{1}{2}
$$

which is again an inverted-U curve in $S$.

\section{Conclusions}

We have shown that a realistic U-relation between market size and concentration emerges naturally in a textbook Cournot model with endogenous cost reduction and entry, even if the conditions of Sutton (1991) and Vives (2008) for a lower bound on concentration are not satisfied. This simple result emerges also with more general demand functions and with imperfect substitutability. When there are positive 
set-up costs, concentration should be higher in small (local) markets and in large (global) markets, while it should be low in markets of intermediate size. Moreover concentration would be negatively correlated with prices only in small markets, but not in large ones. This result may stimulate additional empirical research. 


\section{References}

Dasgupta, Partha and Joseph Stiglitz, 1980, Industrial Structure and the Nature of Innovative Activity, The Economic Journal, 90 (358), 266-93

Ellickson, Paul, 2007, Does Sutton Apply to Supermarkets?, The RAND Journal of Economics, 38 (1), 43-59

Etro, Federico, 2008, Stackelberg Competition with Endogenous Entry, The Economic Journal, 118, 1670-1697

Etro, Federico, 2010, Endogenous Market Structures and Contract Theory, European Economic Review, in press

Etro, Federico, 2011, Endogenous Market Structures and Strategic Trade Policy, International Economic Review, 52, 1, 63-84

Etro, Federico and Andrea Colciago, 2010, Endogenous Market Structures and the Business Cycle, The Economic Journal, 120, 1201-34

Kovac, Eugen, Vinoslav Vinogradov. and kresimir Zigic, 2010, Technological Leadership and the Persistence of Monopoly under Endogenous Entry: static versus dynamic analysis, Journal of Economic Dynamics $\&$ Control, in press

Mankiw, Gregory and Michael Whinston, 1986, Free Entry and Social Inefficiency, RAND Journal of Economics, 17, 1, 48-58

Sutton, John, 1991, Sunk Costs and Market Structure, MIT Press, London

Tandon, Pankaj, 1984, Innovation, Market Structure, and Welfare, The American 
Economic Review, 74 (3), 394-403

Vives, Xavier, 2008, Innovation and Competitive Pressure, Journal of Industrial Economics, 56 (3), 419-469 